\title{
Surgeons should not willingly believe what they wish
}

\author{
Ko Bando, MD, PhD
}

\author{
From the Department of Cardiac Surgery, The Jikei University School of Medicine, Tokyo, Japan. \\ Disclosures: Author has nothing to disclose with regard to commercial support. \\ Received for publication Nov 15, 2018; accepted for publication Nov 15, 2018. \\ Address for reprints: Ko Bando, MD, PhD, Department of Cardiac Surgery, The Jikei University School of Med- \\ icine, 3-25-8, Nishi Shimbashi, Minato-ku, Tokyo 105-8461, Japan (E-mail: kobando@jikei.ac.jp). \\ J Thorac Cardiovasc Surg 2019; 157:e117-8 \\ $0022-5223 / \$ 36.00$ \\ Copyright (c) 2018 by The American Association for Thoracic Surgery \\ https://doi.org/10.1016/j.jtcvs.2018.11.056
}

Despite major advances in diagnostic modalities and antimicrobial therapies, prosthetic valve endocarditis (PVE) continues to be a very serious complication. It occurs with an incidence of $0.3 \%$ to $1.2 \%$ per patient year after surgical aortic valve replacement (SAVR), ${ }^{1}$ with associated mortality rates of up to $38 \%$ for early PVE (within 1 year) and $25 \%$ for late PVE (beyond 1 year). ${ }^{1}$

Transcatheter aortic valve replacement (TAVR) is increasingly used to treat patients with severely symptomatic aortic stenosis who are at high or prohibitive surgical risk. ${ }^{2}$ Data on TAVR-PVE are limited and conflicting. Although a single-center experience indicated a greater than $3 \%$ incidence of TAVR-PVE, ${ }^{3}$ a prospective randomized cohort, ${ }^{4}$ a large multicenter registry, ${ }^{5}$ as well as a metaanalysis $^{6}$ indicated a 1-year incidence of TAVR-PVE between $0.6 \%$ and $1.4 \%$, which is similar to that of SAVR-PVE.

According to a recent multicenter registry ${ }^{7}$ and metaanalysis, ${ }^{6}$ TAVR-PVE is associated with an in-hospital mortality of $37 \%$ to $42 \%$ and a 2 -year mortality rate of $67 \%$, which is roughly 2 -fold greater than that of contemporary SAVR-PVE. Interestingly, surgery was performed in 50\% of SAVR-PVE cases whereas only $10.8 \%$ of TAVR-PVE cases involved infected TAVR valves and subsequent redo SAVR. This very low rate of valve surgery is likely due to the very high risk of such patients, in addition to the potential technical difficulties of removing a stent frame adherent to a severely calcified native valve attached to the aortic valve annulus.

Nguyen and colleagues ${ }^{8}$ recently reported the minimally invasive removal of an infected Edwards S3 transcatheter aortic valve and subsequent surgical prosthetic valve implantation via right anterior minithoracotomy and peripheral cardiopulmonary bypass using the common femoral vein and femoral artery.

Although this approach may be ideal for vulnerable, high-risk patients associated with various comorbidities, we must remember that this report represents a best-case scenario performed by very experienced surgeons with a minimally invasive surgical technique. applied to surgeons.

\section{References}

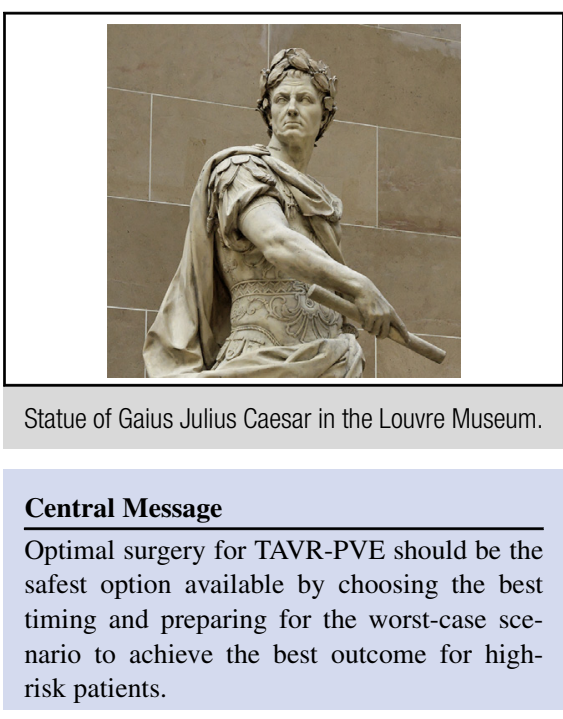

See Article page e113.

Typically, the diagnosis of TAVR-PVE by TEE and computed tomography alone is challenging. Wellestablished echocardiographic criteria for SAVR-PVE including "abscess," "new partial dehiscence of prosthetic valve," and "new valvular regurgitation" are not easily applicable in the context of TAVR-PVE. Incipient vegetation in the free space between prosthetic TAVR material and a severely calcified native aortic valve are particularly difficult to detect by TEE.

Second, decision making by a heart and endocarditis team is the gold standard for medical and surgical treatment options for PVE, and only cardiac surgeons should lead discussions regarding optimal timing and the appropriate surgical approach. Because of the nature of the initial TAVR implantation, patients and cardiologists readily expect minimally invasive surgery for even high-risk, complicated cases such as this one. Only surgeons can explain the possible nightmare scenario, which includes the risk of possible annular reconstruction and root replacement due to the difficult explantation of transcatheter heart valves and possible abscess extension to the annulus.

We have to remind ourselves that Julius Caesar's proverb "People willingly believe what they wish" should not be

1. Habib G, Lancellotti P, Antunes MJ, Bongiorni MG, Casalta JP, Del Zotti F, et al. 2015 ESC guidelines for the management of infective endocarditis: the Task force 
for the management of infective endocarditis on the European Society of Cardiology (ESC). Endorsed by: European Association for Cardio-Thoracic Surgery (EACTS), the European Association of Nuclear Medicine (EANM). Eur Heart J. 2015;36:3075-128.

2. Nishimura RA, Otto CM, Bonow RO, Carabell BA, Erwin JP III, Guyton RA, et al; American College of Cardiology/American Heart Association Task Force on Practice Guidelines. 2014 AHA/ACC guideline for the management of patients with valvular heart disease: a report of the American College of Cardiology/American Heart Association Task Force on practice guidelines. J Am Coll Cardiol. 2014;63: e57-185.

3. Olsen NT, Backer OD, Thyregod HGH, Vejlstrup N, Bundgarrd H, Søndergaard L, et al. Prosthetic valve endocarditis after transcatheter aortic valve implantation. Circ Cardiovasc Interv. 2015;8:e01939.

4. Kodali SK, Williams MR, Smith CR, Svensson LG, Webb JG, Makkar RR, et al; PARTNER Trial Investigators. Two-year outcomes after transacted or surgical aortic valve replacement. $N$ Engl J Med. 2012;366: 1686-95.

5. Amat-Santos IJ, Messika-Zeitoun D, Eltchaninoff H, Kapadia S, Lerakis S, Cheema AN, et al. Infective endocarditis after transcatheter aortic valve implantation: results from a large multicenter registry. Circulation. 2015;1566-74

6. Wang J, Yuan W, Dong R, Liu W, Wang L, Shen H, et al. Transcatheter versus surgical aortic valve replacement-associated infective endocarditis: a meta-analysis of 16 studies. J Thorac Cardiovasc Surg. 2019 [In press].

7. Regueiro A, Linke A, Latib A, Ihlemann N, Urena M, Walther T, et al. Association between transcatheter aortic valve replacement and subsequent infective endocarditis and in-hospital death. JAMA. 2016;316:1083-92.

8. Nguyen TC, Rice RD, Umana-Pizano JB, Loyalka P. Minimally invasive removal of an infected Edwards S3 transcatheter aortic valve. J Thorac Cardiovasc Surg. 2019;157:e113-6. 